\title{
Movimientos Sociales y acción colectiva como bases de la filosofía latinoamericana
}

\author{
Nazareno Bravo \\ INCIHUSA-CONICET, Mendoza, Argentina. Email: nbravo@mendoza-conicet.gob.
}

\begin{abstract}
Resumen: La propuesta del filósofo Arturo Roig (Mendoza, Argentina 1922-) en torno a la existencia de una moral de la protesta en la filosofía latinoamericana, posee aspectos que se consideran importantes para el análisis sociológico. El autor hace alusión a una tradición moral desarrollada en América Latina desde los inicios de su historia y en estrecha vinculación con los movimientos de liberación y las movilizaciones sociales llevadas a cabo por los sectores subalternos. Lo que se pretende es analizar una serie de fenómenos colectivos contemporáneos emergentes en Argentina, como forma de comprender los procesos que subyacen a la conformación de un pensamiento latinoamericano que busca resquebrajar totalidades opresivas.
\end{abstract}

Palabras clave: Filosofía latinoamericana, Acción colectiva, Movilización, Moral de la protesta

\section{Social Movements and collective action as bases of Latin American philosophy}

\begin{abstract}
The proposal of philosopher Arturo Roig (Mendoza, Argentina 1922-) on the existence of a morality of protest in Latin American philosophy, has aspects considered significant for sociological analysis. The author refers to a moral tradition developed in Latin America since the beginnings of its history, and in close relation with liberation movements and social mobilizations carried out by subordinated sectors. What is pursued here is to analyse a series of contemporary collective phenomena emerging in Argentina, as the means to understand the processes that underly the conformation of a Latin American thought that seeks to crack oppressive totalities.
\end{abstract}

Key words: Latin American philosophy, Collective action, Mobilization Morality of protest

\section{Movimentos sociais e ação coletiva como bases da América filosofia americana}

Resumo: A proposta do filósofo Arturo Roig (Mendoza, Argentina 1922) sobre a existência de um protesto moral na filosofia latino-americana, tem aspectos que são considerados importantes para a análise sociológica. $\mathrm{O}$ autor refere-se a uma tradição moral desenvolvidos na América Latina desde o início de sua história, estreitamente ligada com os movimentos de libertação e as mobilizações sociais realizadas pelos subalternos. O objetivo é analisar uma série de fenômenos coletivos 
contemporâneos emergentes na Argentina, como uma forma de compreender os processos subjacentes à formação de um pensamento latino-americano que visa crack totalmente opressiva.

Palavras-chave: Filosofia da América Latina, Ação Coletiva, Mobilização, Moral do protesto.

$$
* * *
$$

\section{Introducción}

El presente artículo busca destacar las posibilidades analíticas que para el trabajo sociológico posee la propuesta del filósofo mendocino Arturo Roig y que se vincula con la presencia de una moral de la protesta en la filosofía latinoamericana. En buena parte de su obra, el autor hace alusión a una tradición moral desarrollada en América Latina desde los inicios de su historia y en estrecha vinculación con las movilizaciones sociales acaecidas a lo largo y a lo ancho de nuestro continente. Dicha tradición puede ser justipreciada a partir del desarrollo de una serie de conceptos y elementos centrales, que resulta fundamental destacar. Entre ellos cabe remarcar, por un lado, el denominado a priori antropológico y, por el otro, la idea de continuos comienzos y recomienzos del pensar latinoamericano.

El presente artículo se propone utilizar los conceptos nodales de dicha propuesta ético-filosófica, en el análisis de algunos de los casos de participación política novedosa que, junto a otros similares ocurridos en la América Latina contemporánea, renovaron las discusiones teóricas sobre la acción colectiva y la movilización social.

Se tendrán en cuenta aquí, algunas de las manifestaciones más llamativas y recientes de la denominada acción colectiva en el contexto argentino: los “piquetes" o cortes de ruta de los trabajadores desocupados y los “escraches" o "funas" (para el caso chileno) de la agrupación de derechos humanos, H.I.J.O.S. ${ }^{1}$

A continuación se presentan en forma resumida, algunas de las características que poseen los conceptos centrales que se intenta desarrollar. Respecto de la noción de a priori antropológico, una conocedora de la obra de Roig, sostiene lo siguiente:

“El a priori antropológico -posición sujetiva que implica la autoconciencia y el autorreconocimiento de sí como valioso y que Roig considera condición de posibilidad de una filosofía latinoamericana- posee un aspecto ético. Por una parte, es expresión del principio conativo de perseverancia en el ser, que Spinoza atribuye a todos los entes; pero, además y en la medida en que está referido a la condición humana, supone el reconocimiento de la dignidad intrínseca de todo hombre y de su valor como fin en sí mismo. Este reconocimiento empero no es de carácter puramente teórico ni surge 
“naturalmente” en las relaciones humanas; según Roig el mismo se origina históricamente cuando tiene lugar un proceso de emergencia, que siempre se encuentra impulsado por necesidades humanas insatisfechas. De este modo, la afirmación de la dignidad humana está asociada en la historia al fenómeno de la emergencia social; además siempre se da acompañada del surgimiento de formas de decodificación espontánea del discurso opresor, que luego se expresan en las variadas y ricas modalidades del discurso popular -dichos, canción, cuento fantástico, poesía, teatro satírico, etcétera-” (Fernández 2001: 124).

Esto es, la existencia de una filosofía latinoamericana supone la presencia de un sujeto activo que, a partir de una práctica concreta vinculada con la satisfacción de demandas, reconoce su importancia y dignifica su vida. Cabe destacar que se hace alusión a un sujeto colectivo que construye una visión crítica y muchas veces transformadora, al calor de procesos sociales vinculados, muchas veces, a proyectos transformadores.

Una de las características destacadas de esa tradición filosófica y moral, es que ha sido elaborada no sólo por "hombres de palabra" sino, sobre todo, por hombres de acción. Esto es, no necesariamente -ni siquiera principalmente- por intelectuales profesionales o filósofos, lo que ayuda a comprender, en parte, su carácter muchas veces "incongruente"/ "inconexo".

“Es posible hablar de una práctica y un pensamiento morales propios de nuestra América, que se han ido conformando y expresando en la sabiduría oral de nuestras gentes así como en los textos de nuestros escritores sociales y nuestros literatos” (Roig 2002: 51)

Es este, otro de los elementos que sirven para comprender la importancia del par conceptual mencionado, comienzos y recomienzos, aspecto que puede ser vinculado con el carácter dinámico que poseen los procesos sociales en los que se conforma dicho pensamiento y que deben ser ubicados al interior de las luchas -nunca definitivas- que en nuestro Continente, llevaron y llevan a cabo los sectores subalternos ante las distintas manifestaciones de los poderes de turno y que persiguen la quiebra de totalidades opresivas que, a su vez, dificultan o impiden las diversas formas de emergencia.

Por su parte, los valores que se erigen como columna vertebral de este pensamiento moral, son el disenso (en estrecha vinculación con el ejercicio de la función utópica) y la afirmación de una alteridad que sirve como foco de resistencia ante una lógica dominante que no contempla otredades (Roig 2002: 111). Dichos valores surgen, en la propuesta del filósofo, al calor de luchas sociales históricas entre las que señala los movimientos independentistas del siglo XVIII y la labor de las Madres de Plaza de Mayo desde los tiempos de la dictadura militar argentina entre 1976 y 1983 (Cfr. Roig 1993: 182). 
Como se dijo en un principio, se abre la posibilidad de realizar una lectura situada de la palpables de disenso y resistencia sociales, un tanto más recientes que las mencionadas por Roig y -aquí el desafío- utilizando herramientas que ofrece la sociología.

En primer lugar se hará referencia a los fenómenos sociales que servirán de vehículo para realizar el presente estudio. En primer lugar, se aludirá a las manifestaciones de denuncia encabezadas por la agrupación H.I.J.O.S. y, posteriormente, a los cortes de ruta llevados a cabo por los desempleados, como forma de protesta.

\section{Comienzos y recomienzos de la lucha por la memoria: "Si no hay justicia, hay escrache"}

El escrache nace en la Argentina como una herramienta política de denuncia implementada por la agrupación H.I.J.O.S. (Hijos e Hijas por la Identidad y la Justicia contra el Olvido y el Silencio) a partir de 1996, un año después del surgimiento de esa organización que nuclea a hijos e hijas de desaparecidos, ex presos políticos y exiliados durante la última dictadura militar argentina. Proveniente del lunfardo, la palabra escrache es retomada para hacer referencia al señalamiento y "descubrimiento" de los implicados en violaciones a los derechos humanos durante la última dictadura militar en Argentina. Prácticamente la totalidad de los militares y civiles que participaron en la represión estatal -que dejó un saldo de 30.000 detenidos desaparecidos, 10.000 presos políticos, miles de exiliados y cesanteados- quedaron absueltos y libres en democracia a instancia de leyes parlamentarias dictadas durante el gobierno de R. Alfonsín (Ley de Punto Final y Ley de Obediencia Debida) y de los indultos del presidente C. Menem.

A pesar de que dichas leyes fueron dictadas bajo un supuesto espíritu reconciliador, la sensación de impunidad y la debilidad de las instituciones democráticas que generaron, hallaron en el escrache una vía de expresión y denuncia hasta el momento inédita en la política argentina. Si bien las numerosas filiales de H.I.J.O.S. en todo el país llevaron esta práctica atendiendo a las particularidades de cada provincia, pueden señalarse una serie de características compartidas por todos ellos: los escraches suponen la búsqueda de información referida al pasado y el presente del acusado, y exponen ante la mirada pública su foto y dirección; contando con estos datos se inicia la tarea de organización de una marcha que culmina (en aquellos casos en que los operativos policiales lo permiten) en la puerta de su casa, donde se desarrolla un acto más bien breve en el que se leen los datos principales que lo implican con la represión, como el cargo ocupado, las denuncias que sobre él pesan y su actual actividad (en varios casos vinculada al aparato represivo o estatal); para finalizar el escrache se arroja pintura roja en la fachada de la vivienda como forma de señalar el domicilio del represor o cómplice de la dictadura. Durante todo el trayecto, la marcha va acompañada por las restantes agrupaciones de derechos huma- 
nos, movimientos políticos y sociales y por los propios vecinos del escrachado.

El objetivo principal del acto es conseguir una condena moral por parte de la sociedad hacia los represores y llamar la atención respecto de una problemática que intentaba ser acallada desde los tiempos del gobierno de facto. De allí que una de las preocupaciones más evidentes para los manifestantes resida en la búsqueda de apoyo por parte de los vecinos del represor y la población en general -en tanto ciudadanos no relacionados directamente con las víctimas, pero víctimas ellos mismos del modelo de país que instaló la dictadura-.

Sin lugar a dudas, el escrache debe ser incluido en la lista de las novedosas experiencias políticas surgidas en el contexto democrático reciente, cuyas formas de ejercicio mutaron fuertemente respecto de los modos pre-dictatoriales (Cfr. Giarraca 2001; Bravo 2008). Tanto los escraches como los cortes de ruta o las asambleas populares pueden ser comprendidos como prácticas políticas que, en principio, no tienen una vinculación directa con las agrupaciones partidarias tradicionales; esto no supone, empero, un rechazo a la política, sino más bien la búsqueda de nuevas formas de practicarla, basadas en la obtención de consensos y la democracia directa. Pero no es únicamente el novedoso perfil político que supone el escrache lo que puede aquí destacarse, ya que esta práctica viene a cuestionar un estado de las cosas que por varios motivos parecía inamovible.

En principio, debe destacarse que la época en la que surgen los escraches no se caracterizaba, justamente, por la centralidad de la temática de los derechos humanos o la revisión del pasado reciente. En más de 10 años de democracia, la cuestión de la justicia fue paulatinamente quedando a la sombra de nuevas urgencias sociales, como el desempleo o la pobreza, pero también -y a pesar del poco consenso con que contaron en su momento- las denominadas leyes de impunidad significaron un duro revés para los organismos de derechos humanos y su lucha por la justicia. Más allá de las numerosas diferencias políticas que puedan marcarse, la gestión de Alfonsín y Menem construyeron e impusieron en conjunto, un límite concreto a la posibilidad de justicia (Acuña 1995). El escrache de H.I.J.O.S. puede ser visto, entonces, como una inesperada manera de resquebrajar el pensamiento hegemónico que sobre el pasado se había erigido.

Puede plantearse que esta manifestación de disenso logró instalarse, no sin dificultades, a partir de la puesta en marcha de uno de los valores centrales de la moral de la protesta: la función utópica. Tal vez aquí radique uno de los principales aportes de la labor de H.I.J.O.S. a la política popular, ya que el escrache supone no sólo la denuncia de impunidad y la complicidad de la Justicia democrática (aquí reside gran parte del disenso que implica), sino que conlleva un modelo de justicia divergente, basada en la toma de conciencia colectiva. Es decir, no sólo es una denuncia, también es una propuesta en acto, una forma de hacerse cargo de la búsqueda de justicia y memoria que no depende de instituciones que de una u otra forma 
colaboraron en la construcción de aquel consenso hegemónico. El hecho de repensar la obtención de justicia logra trascender un asunto puramente judicial, para instalarse en la discusión de otro futuro posible (Roig 1978 y 1987). Porque debe tenerse en cuenta que el escrache no es únicamente pura práctica (ninguna acción colectiva lo es, por otro lado) sino que también es resultado de una elaboración colectiva situada, lo que supone la necesaria construcción de un discurso, unos símbolos y -en definitiva- una mirada crítica y creativa sobre el presente, que permite postular un futuro diferente (Cfr. Fernández 1995).

"Si no hay justicia, hay escrache” es la consigna que sintetiza esta práctica y resulta una frase que debe ser ubicada como parte del árbol genealógico de la lucha por la memoria encabezada por los organismos de derechos humanos y que posee una contundencia única por varios motivos. Fundamentalmente, se trata de una invitación a la acción que se aleja del simple reclamo, más allá de la pertinencia del mismo. Es decir, no existe aquí un pedido menos o más directo a las autoridades de turno, tales como la impactante y necesaria “Aparición con vida” enarbolada durante años por Madres y Abuelas inclusive durante la dictadura. Es necesario reconocer, además, que la consigna de H.I.J.O.S. se ubica en un contexto político en el que se hacen notorias las modificaciones en la relación entre sociedad civil y Estado. Porque si bien el escrache supone un alto grado de autonomía respecto de instituciones cuestionadas, debilitadas o directamente cómplices de la impunidad (en última instancia la condena social depende, justamente, de la propia sociedad); esto no implica su desconocimiento: lo que se busca -por una vía alternativa- es la condena efectiva, la cárcel común y sin privilegios para todos los genocidas. Y es aquí donde este "Si no hay justicia, hay escrache” se emparenta con aquel "Juicio y Castigo a los culpables” que trabajosamente instalaron las Madres años antes. No se trata entonces de una práctica y un discurso desconectados de las luchas anteriores, sino más bien, de una renovación de los repertorios de acción en un contexto político e histórico diferente, en el que aún es necesario reclamar por derechos fundamentales.

Cabe aquí la posibilidad de señalar un recomienzo de la movilización por justicia y memoria. Y justamente son los continuos comienzos y recomienzos los que caracterizan a la moralidad de la protesta. Ésta es, tal vez, una de las nociones que facilita de modo más claro, la posibilidad de captar el dinámico y continuo proceso de elaboración que supone la filosofía moral. Cada "recomienzo" que pueda señalarse permite establecer la recurrente vocación de movilización y colectivización de demandas que atraviesan la historia americana, como así también la enorme creatividad que supone la actualización de repertorios utilizados por los actores movilizados del continente.

"Nos interesa particularmente [...] la continuidad de voces que de época en época van mostrando el ejercicio de la sujetividad del hombre latinoamericano. Los textos en los que se manifiesta ese tipo discursivo nos ponen en la pista de los comienzos y recomienzos 
[...] de una sola filosofía, nuestra filosofía latinoamericana [...]. En todos los casos es posible descubrir, de modo patente, la presencia de un sujeto que asume su propia sujetividad, vale decir, su propia realidad social de una manera no ajena a la exigencia de transformación, porque esa realidad y su propia naturaleza en cuanto sujeto, son transformables, es decir, son históricas y no 'naturales' [...]. Este tipo de manifestaciones se encuentra más cerca de la literatura de protesta y de denuncia y hasta de justificación de los actos de afirmación y rebeldía, y es por eso mismo marginal a la producción literaria académica y hegemónica, por donde los comienzos y recomienzos de que hablamos vienen a entroncarse en más de una ocasión, fácilmente, con formas literarias y musicales de origen popular”. (Roig 1993: 167 a 169).

Pero también, la presencia del par “comienzos / recomienzos” resulta una señal de lo dificultosa que resulta la construcción social y política para los sectores dominados, quienes -en una batalla desigual con sus dominantes- se ven obligados a retomar luchas inconclusas de su historia como pueblo. De allí que Roig hable de una "dialéctica discontinua” en la configuración discursiva de esa moral emergente.

"Hemos sostenido que no hay un comienzo de la Filosofía latinoamericana propiamente dicha, sino recomienzos. Asimismo hemos aventurado la tesis de una historiografía en la que lo episódico posee una particular presencia, no extraña a aquel recomenzar. Una filosofía Latinoamericana [...se nos presenta...] como un enunciado de discursos circunstanciales que han sido para cada época diagnóstico, denuncia, proyecto y también, por cierto, compromiso”. (Roig 2008: 157).

Ahora bien, para justipreciar el valor que poseen las experiencias de rebeldía popular, debe marcarse también la capacidad que poseen las clases dominantes de imponer su cosmovisión al resto de la sociedad, al tiempo que logran (parcialmente, con menos o más suerte, no sin dificultades, etcétera) eclipsar la memoria histórica de sus adversarios (Cfr. Benjamin 2002). De allí que las luchas no impliquen únicamente un cuestionamiento al status quo epocal, sino una disputa por el pasado que resulta central para no limitar los fenómenos colectivos a reclamos puntuales y sectoriales desconectados de la historia, en un puro presente.

En definitiva, el escrache puede ser apreciado tanto como ejemplo de un modo de autorregulación social, como de una manifestación emergente vinculada a las modificaciones en la práctica de la política, propias de una etapa de transformaciones y reacomodamientos sociales. Al mismo tiempo es el corolario de una relectura particular de la historia reciente, en la que se encadenan impunidades por parte del aparato estatal dictatorial y democrático; pero donde también surgen resistencias basadas en la búsqueda de la dignidad como base impostergable para pensar un futuro en el que quepan los inconclusos proyectos pasados. 


\section{De trabajadores a desocupados y de desocupados a piqueteros. Acción colectiva y disputas por la identidad}

Sin dudas que el fenómeno piquetero, sirvió de punta de lanza para una actualización de los debates políticos y teóricos de los estudios sociales locales en los últimos años. La “aparición” de un nuevo actor colectivo puede ser analizada como efecto de una serie de procesos sociales que se vinculan con transformaciones estructurales de gran envergadura y el impacto que éstas provocaron en el orden social y su correlato en las subjetividades. Debe reconocerse, empero, que será en la experiencia de los sectores populares donde se refleje gran parte de las principales y más acuciantes implicancias de la nueva situación: la falta de empleo, vivenciada como resultado de fallas personales especialmente en los primeros años de la década de 1990, y la imposición de una lógica individualista a ultranza convirtieron, en muchos casos, a sus pares en una amenaza. Todo ello fue modificando la vida de estos sectores. El mundo conocido -la fábrica, el barrio, el sindicato o el partido- y las expectativas que allí se tejían -el progreso, la transformación social, la solidaridad- mutó en lugares en los que primaba la incertidumbre y se edificaba la marginación (Svampa 2000).

Durante décadas, los sectores populares lograron definirse y actuar a partir de su condición de trabajadores. La variedad de situaciones que pudieran señalarse al interior del colectivo "clase trabajadora" o "pueblo", no impide reconocer los elevados niveles de homogeneidad que poseían dichos sectores. Esta identidad, tenía un correlato en cuanto a los modos de organizarse y actuar conjuntamente, a través de partidos y sindicatos, lo que fortalecía, a su vez, una identidad colectiva particular.

Los estudios sociales contemporáneos, construyeron el perfil de los sectores populares atendiendo especialmente a lo novedoso de este complejo proceso y resaltando las diferencias respecto del modelo anterior, en clave de rupturas, ausencias y caídas. Este tipo de decisiones analíticas no conforman solamente un interés académico que importe de manera exclusiva a los propios científicos, sino que incide fuertemente en las posibilidades de comprender y actuar sobre la realidad por parte de la sociedad toda, incluidos claro está los propios sectores populares. Este es el marco donde puede realizarse una lectura crítica de los modos de aproximación a dichas problemáticas. Es que, más allá de las coincidencias existentes en cuanto a la conformación de un nuevo panorama global, el país fue testigo -especialmente a partir de la mitad de la década de 1990- de la emergencia de variadísimas respuestas por parte de la sociedad civil a la apremiante situación de crisis.

Y tal vez sea allí donde resida una de las principales diferencias respecto del cuadro planteado por aquellos autores que abordaron la problemática en otros contextos, como el europeo, desde donde provienen buena parte de los insumos teóricos que se utilizan para pensar la sociedad contemporánea. Es decir, si los análisis sociales habían logrado poner de mani- 
fiesto las rupturas con el escenario anterior, hizo falta revisar buena parte de tales supuestos para reconocer y comprender el desarrollo de novedosos procesos colectivos de participación y organización que derivaron, entre otros fenómenos, en los cortes de ruta.

Uno de los elementos que debe ser tenido en cuenta para comprender el fenómeno piquetero -y que servirá de vehículo para profundizar los objetivos de este trabajo- se vincula con un proceso dialéctico de construcción / deconstrucción de identidad colectiva que puede ser relacionado con la afirmación de alteridad que supone la moralidad emergente.

Cuando se hizo evidente que la relativa pero existente homogeneidad de la clase trabajadora argentina se fragmentaba una y otra vez hasta conformar un panorama donde reinaba la diversidad y el desconocimiento de gran parte de lo que allí ocurría, se produjo lo que algunos autores han graficado con la imagen de una metamorfosis acelerada del "trabajador" en "pobre":

"La denominación de pobres de los que eran considerados hasta entonces trabajadores comporta una redefinición de los problemas sociales y de los dispositivos capaces de servir al combate de la nueva plaga. A continuación, esta nueva problematización forma parte de la manera en que los individuos _viven’ su situación, lo que la hace entrar así en relación directa con las modalidades de la movilización colectiva” (Merklen 2005: 111).

La construcción de identidad es un complejo y dinámico proceso en el que entran en juego las posibilidades y herramientas de que disponen diversos sectores en un momento dado, para imponer su mirada a los demás. Se trata de una edificación nunca definitiva, aunque con etapas que pueden ser postuladas como estables, sostenidas en el tiempo. Y este pasaje de "trabajador" a "pobre", que destacan las investigaciones recientes, pareció, en muchos momentos, convertirse en permanente.

Lo que se quiere destacar con este asunto, es la capacidad de los sectores dominantes (dominantes en lo económico y político, pero también en lo intelectual) de imponer no sólo modelos de exclusión, sino nomenclaturas que condicionan las posibilidades para pensar y actuar lo social (Cfr. Gramsci 2003). Este condicionamiento alcanza, de más está aclararlo, a los propios mencionados, quienes no sólo llevan la peor parte del proceso sino que ven limitadas las oportunidades de afrontar la situación como colectivo, en tanto que lo único que aparentemente comparten es su condición de pobreza. Además ya no se trata de una pobreza superable, transitoria o al menos considerada digna como antaño ya que los sujetos que transitan esta situación en la actualidad, quedan limitados por una mirada dominante que lo ubica como pasivo o peligroso, al que sólo cabe asistir o reprimir según el caso.

Sin embargo, fue desde la acción de estos pobres (trabajadores sin 
trabajo), de donde surgió uno de los Movimientos más novedosos e interesantes de las últimas décadas; asunto que podría analizarse tomando en cuenta algunos de los principales preceptos del pensamiento moral que se quiere abordar. En principio, debe destacarse la importancia del a priori antropológico, como condición previa a la posibilidad de cuestionar el orden hegemónico desde un espacio colectivo (Pérez Zabala 2005).

Roig toma este concepto kantiano para dar cuenta de la relevancia e importancia que posee el momento de afirmación de un sujeto histórico, "un sujeto que para conocer el mundo se ponía en un acto de afirmación de sí mismo, comenzando por el reconocimiento del valor de la subjetividad y de su autoconocimiento como hechos históricos” (Roig 2002: 24).

La condición de pobreza resulta poco y nada pertinente para postularse como colectivo con capacidad de acción, especialmente si se consideran tanto las diferencias con la identidad colectiva que había encolumnado a los sectores populares poco tiempo atrás ("los trabajadores", "el pueblo"), como la construcción estigmatizante que se fue instalando del concepto de pobreza. De allí que la aparición del Movimiento Piquetero, no pueda ser comprendida si no se tiene en cuenta un momento necesario de elaboración y cuestionamiento crítico de dicha atribución identitaria, que permitiese la superación del estigma y la postulación de una identidad emergente, sostenida en novedosos parámetros de participación, movilización y expresión social. Aquí radica un aporte específico de la propuesta de Roig, ya que permite visualizar y apreciar el necesario momento de autoafirmación colectiva que implica todo proceso de transformación social.

“La posición de sujeto -que llama Roig ‘a priori antropológico’ y que configura el rasgo distintivo de la humanidad- implica siempre una emergencia y una resistencia frente a formas de sometimiento o marginación [...]. La condición humana se pone de manifiesto cuando el ser humano, aplastado, despreciado, marginado, responde afirmando: ‘yo también soy humano'. Afirmamos nuestra condición o índole cuando ejercemos el a priori antropológico, esa 'posición de sujeto' que emerge, resiste y recomienza. En este sentido, la condición humana es una meta y un camino de lucha para alcanzarla.[...]. Y las luchas contra las diversas formas de alienación 'sólo son posibles si el sujeto comienza sabiéndose sujeto". (Fernández 2005: 87).

En un panorama caracterizado por la polarización social, la marginación (espacial y social) y el individualismo neoliberal, difícilmente la identidad piquetera pudiera ser resultado de la acción y la palabra de un sector social que no fueran los propios sectores populares. Es así como aquel a priori antropológico ("Tenernos a nosotros mismos como valiosos”) permite comprender, no sólo el surgimiento piquetero, sino su valor como proceso social y político en el que "a través de su propia enajenación, surge con voz de protesta y de denuncia” (Roig 2002: 112). 
Memoria colectiva, experiencia organizativa, rechazo o imposibilidad de utilizar las vías tradicionales de solución de conflictos sociales y búsqueda de caminos alternativos para salvar situaciones caracterizadas por acuciantes problemas cotidianos, resultan ser algunos de los numerosos elementos que, de diversa manera y con distinta intensidad, se combinaron para dar lugar a la emergencia de tales fenómenos.

En cierta forma es dable pensar que la proliferación de este tipo de experiencias, ocurridas a lo largo y ancho del territorio, logró resquebrajar paulatinamente un panorama que, a primera vista, parecía condenado a la anomia, la disolución de los lazos sociales, la desintegración, la polarización social y la escasez de espacios organizativos.

\section{Conclusiones: Acción colectiva y moralidad de la protesta. La dignidad como principio de disenso}

Se inició este recorrido con la intención de considerar la productividad teórica de categorías filosóficas provenientes del pensamiento de Arturo Roig, a partir del análisis de algunos de los fenómenos sociales más llamativos de los últimos años. Se buscó en ellos, la presencia de elementos de resistencia, crítica y transformación que forman parte de una moralidad de la protesta como característica central de la filosofía latinoamericana.

Desde allí, se postuló que tanto los escraches como los piquetes -en tanto prácticas concretas llevadas a cabo por colectivos emergentes- poseen rasgos que permiten ubicarlos como manifestaciones recientes de un modo de elaborar, proponer y activar demandas, que los enlazan con movimientos sociales históricos de nuestro continente.

Se trata de un pensamiento moral, de una filosofía no-sistematizada pero palpable, que emerge como respuesta en momentos críticos de nuestra historia. Claro que sería erróneo pensar en ciclos naturales de emergencia y desconocer el carácter necesariamente activo y colectivo que la misma supone (Mahr 2003).

También es necesario situar esta filosofía moral, en un contexto histórico y social particular, como el latinoamericano. La aparición periódica de manifestaciones de una moralidad de la protesta, habla a las claras no sólo de la capacidad y vocación liberadora de los sectores populares a lo largo de la historia, sino también de una situación de dominación sostenida durante siglos. Este es un elemento que debe ser tenido en cuenta para comprender lo "no-sistemático" de este pensamiento moral ya que, justamente, una de las estrategias que poseen los grupos dominantes para imponerse es la deshistorización de las luchas populares. Pero también, en tanto estrategia de dominación, debe hacerse referencia a la apropiación parcial y la resignificación de algunos elementos (fundamentalmente discursivos) de la moralidad emergente por parte de los poderes de turno, a fin de neutralizar demandas y vaciar su contenido. Lo dicho busca resaltar el carácter 
dinámico y dificultoso que posee la construcción de una filosofía asentada en prácticas y cosmovisiones divergentes.

Pero los continuos "recomienzos" de la moralidad emergente (aquí se propuso su análisis a partir de la práctica del escrache) implican, a su vez, un fenómeno que Roig denomina "reordenamiento de los saberes y de las prácticas” (Roig 2002: 113). Es decir, los sectores movilizados logran resquebrajar los mandatos impuestos a partir de una acción dialécticamente vinculada con la elaboración y resemantización de categorías.

El pasaje de "trabajador" a "pobre" (identidad impuesta a los sectores populares) y de "pobre" a "piquetero" (propuesta identitaria crítica, cuestionadora y desafiante enarbolada por parte de los mismo sectores) señala no sólo un tema de conceptualización sino la búsqueda de vías de diferenciación de saberes teóricos dominantes y la elaboración de técnicas políticas propias, aunque no desconectadas ni de la historia, ni de la realidad presente.

Si tuviera que postularse un hilo conductor para pensar la moralidad de la protesta, podría apelarse a una categoría que atraviesa su historia: la dignidad. Las luchas independentistas, la resistencia indígena, los reclamos obreros o la acción de las Madres de Plaza de Mayo, comparten (más allá de las muchas diferencias históricas que puedan señalarse) este elemento común. El cuestionamiento a un orden establecido, injusto y aniquilador de las diferencias se asienta en la crítica y la rebelión ante un pensamiento hegemónico que basa su dominio en la explotación y sojuzgamiento. El rechazo a la postulación de seres humanos como medios (para obtener riquezas, poder, legitimidad, etcétera) y no como fines, puede señalarse como disparador de la protesta en cualquiera de los ejemplos citados. De allí que las disidencias y los proyectos emergentes broten en torno a la necesidad de recobrar o restituir experiencias humanas que los sectores dominantes logran privatizar para su provecho exclusivo: libertad, autonomía, justicia.

La dignidad como idea reguladora, emerge como una necesidad fundamental no siempre cumplida, como núcleo de la disidencia y brújula para la acción; más allá de que sus manifestaciones puedan corporizarse históricamente en vías expresivas de lo más diferentes entre sí -en cuanto a su formato o modo de verbalización-. La búsqueda de "nuevos universales sobre los cuales organizar la conducta humana de un modo no ajeno a formas de movilidad social y de cambios” (Roig 2002: 111) se encuentra como cimiento de la acción de hombres y mujeres que a lo largo y ancho del continente americano, han ido elaborando trabajosamente, y no sin contratiempos costosísimos, una cosmovisión propia que necesariamente deberá profundizarse al calor de la práctica. 


\section{Nota}

1 "Piquetes" es la denominación que se les da a la acción de impedir el paso de vehículos por parte de los manifestantes que, de esta manera, reclaman y buscan llamar la atención del gobierno y de la ciudadanía. "Escrache” es una palabra que proviene del uso popular del castellano y puede ser comprendida como un acto de señalamiento, acusación o denuncia. En Chile, la palabra "funa" es utilizada en forma similar. 


\section{Bibliografía}

Acuña, C. y otros (1995), Juicio, castigo y memorias; derechos humanos y justicia en la política argentina, Nueva Visión, Buenos Aires.

Benjamin, Walter (2002), “Tesis sobre la filosofía de la historia”, en Ensayos, I, 2 ed., Editora Nacional, Madrid.

Bravo, Nazareno (2008), Acción colectiva y construcción de identidad en sectores populares de la Argentina actual. El caso de la biblioteca popular del barrio La Gloria en Mendoza, Tesis de Doctorado en Ciencias Sociales, FLACSO, Buenos Aires.

Fernández Nadal, Estela (1995), “La problemática de la utopía desde una perspectiva latinoamericana”, en Arturo Andrés Roig (comp.), Proceso civilizatorio y ejercicio utópico en Nuestra América, Editorial Fundación Universidad Nacional de San Juan, San Juan.

Fernández Nadal, Estela (2001), “Arturo Andrés Roig (1922)”, en Clara Jalif de Bertranou (comp.), Semillas en el tiempo. El latinoamericanismo filosófico contemporáneo, EDIUNC, Mendoza.

Fernández Nadal, Estela (2005), “La condición humana como problema filosófico en Arturo Roig. La conformación de la sujetividad en las fronteras de la contingencia”, en Latinoamérica. Revista de Estudios Latinoamericanos, $\mathrm{N}^{\circ}$ 40, CECYDEL, UNAM, México.

Giarraca, Norma (2001), La protesta social en Argentina. Transformaciones económicas y crisis social en el interior del país, Alianza, Buenos Aires.

Gramsci, Antonio (2003), El materialismo histórico y la filosofía de Benedetto Croce, Nueva Visión, Buenos Aires.

Jelín, Elizabeth (1995), “La política de la memoria. El movimiento de derechos humanos y la construcción democrática en Argentina” en Acuña, Carlos y Otros (op.cit), Nueva Visión, Buenos Aires.

Mahr, Günter (2003), “El aporte de Arturo Andrés Roig a la filosofía contemporánea” en Utopía y Praxis Latinoamericana, $\mathrm{N}^{\circ} 20$, Universidad de Zulia, CESA, Venezuela.

Merklen, Denis (2005), Pobres ciudadanos; las clases populares en la era democrática (Argentina, 1983-2003), Gorla, Buenos Aires.

Pérez Zavala, Carlos (2005), La filosofía latinoamericana como compromiso, ICALA, Río Cuarto.

Roig, Arturo (1978), “Narrativa y cotidianidad: la obra de Vladimir Propp 
a la luz de un cuento ecuatoriano", en Cultura. Revista del Centro de Investigación y Cultura del Banco Central del Ecuador, $\mathrm{N}^{\circ}$ 2, BCE, Quito.

Ídem (1981), Teoría y crítica del pensamiento latinoamericano, Fondo de Cultura Económica, México.

Ídem (1987), "El discurso utópico y sus formas en la historia intelectual ecuatoriana”, en La utopía en el Ecuador, Banco Central y Corporación Editora Nacional, Quito.

Ídem (1993), Rostro y Filosofía de America Latina, EDIUNC, Mendoza.

Ídem (2001), Caminos de la filosofía latinoamericana, Universidad del Zulia, Maracaibo.

Ídem (2002), Ética del poder y moralidad de la protesta; respuestas a la crisis moral de nuestro tiempo, EDIUNC, Mendoza.

Ídem (2008 ), El pensamiento latinoamericano y su aventura, Ediciones El Andariego, Buenos Aires.

Svampa, Maristella (editora) (2000), Desde abajo; la transformación de las identidades sociales, Biblos, Buenos Aires.

Recibido: 01.06.2010

Aceptado: 17.11.2010 